\title{
Problem solving in acute oncology
}

\author{
E Marshall, A Young, P Clark and P Selby (Editors) \\ Publisher: Clinical Publishing, Oxford; 2013; 272 pp. \\ ISBN: 978-1-84692-108-7
}

The 2008 National Confidential Enquiry into Patient Outcome and Death within 30 days of chemotherapy and subsequent formation of the National Chemotherapy Advisory Group were instrumental in the commissioning and subsequent development of 'Acute Oncology' in the UK (National Confidential Enquiry into Patient Outcomes and Death, 2008). This report highlighted that $27 \%$ of cancer patients likely had their death caused or hastened by systemic anti-cancer therapy. As a result, Acute Oncology Services, which are subject to peer review, should now give specialist input during the hospital admission of all suspected new cancer and known cancer patients admitted to hospital with complications related to treatment and/or cancer (National Cancer Action Team, 2011). This recommendation is important as currently, an alarming $20 \%$ of cancer diagnoses are made following an emergency hospital admission (Royal College of Physicians, 2013). The aim of this network-wide service is that following an unplanned hospital admission, there is a route to faster diagnosis, referral and treatment using local pathways leading to improved quality of care. The resulting reduced hospital stay with input from clinicians specialising in oncology is hoped to improve patient satisfaction while being more efficient for health-care providers.

Marshall et al are to be congratulated on their comprehensive review of Acute Oncology internationally as it stands today. It is a timely publication as the numbers of patients diagnosed with cancer are rising coupled with the increased use and variety of anticancer therapies. The impressive group of contributors with a vast array of experience present a very readable, case-based approach to the most common presentations encountered in an Acute Oncology practice. The publication has been supported by the Association of Cancer Physicians.

The book starts with the history, politics and structure of Acute Oncology services both nationally and internationally, which is a fascinating read. The structure of these services differs between countries and also within the same country. It goes on to provide a very practical guide on the management of every day clinical conundrums in Acute Oncology, including how to manage the sick patient appropriately. A good Acute Oncologist will have a broad understanding of general medicine, and this book encompasses welldescribed, up-to-date tools - for example, National Early Warning Scores (NEWS) and the Multinational Association for Supportive Care in Cancer (MASCC) scores. The text is subsequently divided up into complications of cancer treatment (systemic therapy and radiotherapy) followed by complications of cancer itself. The publication exceeded our expectations, in that not only was it well written and clearly laid out, but also it included a wide variety of relevant case-based discussions that are referenced with guidance on suggested further reading. Complications of common chemotherapeutics as well as newer, targeted agents such as anti-angiogenic therapy were included. Occasionally, we felt that more treatment details would be helpful - for example, anti-angiogenic therapyinduced hypertension treatment guidelines (incorporating blood pressure levels, antihypertensive doses, options). However, the level of detail is adequate for the acute oncology setting and details of ongoing specialist management is beyond the remit of this book.

It was particularly helpful to have a section dedicated to the acute management of cancer patients on clinical trials - an area that can be daunting to clinicians who may not be familiar with toxicities seen with newer treatments and the logistical aspects in relation to trial patients (e.g., significance of documentation of adverse events). In addition, the section on acute pain management provides a useful, basic guide in an acute situation.

The book also gives helpful tips on controversial areas often debated about among doctors in the acute situation, such as which patients with ascites might benefit from diuretics and escalation of care to the more intensive environment.

Problem Solving in Acute Oncology will serve as an excellent educational source for those new to the field and has many useful points of revision for those of us already in the specialty. Improving outcomes for our cancer patients such as earlier detection of sepsis and its timely treatment is vital. New cancer diagnoses and oncology-related problems are not uncommon for the average medical take and this book should be of interest to acute general physicians. Acute Oncology is a multidisciplinary specialty and it is possible that in the future, increasing numbers of patients will be risk stratified following initial assessment and then partly treated in the community. Network guidelines, along with those from agencies such as the National Institute for Health and Care Excellence, will be complemented by books such as this whose educational material will increase health-care practitioner confidence, to help ensure robust, safe and up-to-date practice.

\section{ACKNOWLEDGEMENTS}

We acknowledge support from the National Institute of Health Research (NIHR) Biomedical Research Centre.

S Banerjee ${ }^{*, 1}$ and S Stanway ${ }^{2}$

${ }^{1}$ The Royal Marsden Hospital, London, UK and

${ }^{2}$ The Royal Marsden Hospital and Croydon University Hospital, London, UK 


\section{REFERENCES}

National Cancer Action Team (2011) Manual for cancer services. Acute oncology - including metastatic spinal cord compression measures. National Cancer Action Team: London. Available at: www.gov.uk/government/ uploads/system/uploads/attachment_data/file/216121/dh_125889.pdf.

National Confidential Enquiry into Patient Outcomes and Death (2008) For better or worse? A review of the care of patients who died within 30 days of receiving systemic anti-cancer therapy. NCEPOD: London.

Available at: www.ncepod.org.uk/2008report3/Downloads/SACT_report. pdf.

Royal College of Physicians (2013) Acute care toolkit 7: acute Oncology on the acute medical unit.

(c) (1) (2) This work is licensed under the Creative Commons (c) ${ }_{\text {BY }}$ NC SA Attribution-NonCommercial-Share Alike 3.0 Unported License. To view a copy of this license, visit http://creativecommons. org/licenses/by-nc-sa/3.0/ 